\title{
Postconditioning is protective in renal reperfusion injury only in male rats. A gender difference study
}

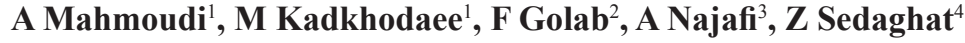 \\ ${ }^{1}$ Department of Physiology, School of Medicine, Tehran University of Medical Sciences, Tehran, Iran \\ ${ }^{2}$ Cellular and Molecular Research Center, Iran University of Medical Science, Tehran, Iran \\ ${ }^{3}$ Department of Anatomy, School of Medicine, Tehran University of Medical Science, Tehran, Iran \\ ${ }^{4}$ Department of Physiology and Pharmacology, School of Medicine, Bushehr University of Medical Sciences, \\ Bushehr, Iran
}

Received: September 28, 2013

Accepted after revision: July 25, 2014

\begin{abstract}
Purpose: We investigated the impact of sex on the protective effect of postconditioning (POC), a series of brief ischemia-reperfusion (IR) cycles at the reperfusion onset, as a recently described novel approach to attenuate renal IR injury. In this study, the left renal pedicles of uni-nephrectomized male and female rats were clamped for 45 minutes followed by 24 hours of reperfusion as IR groups. Uni-nephrectomized, sham-operated male and female rats served as control groups. Ischemic postconditioning was performed using 4 cycles of 10 seconds IR of renal pedicle at the end of the ischemia. Twenty-four hours later, BUN (blood urea nitrogen), plasma creatinine (Cr), and renal histological changes, as well as kidney levels of MDA (malondialdehyde) and SOD (superoxide dismutase) as oxidative stress markers were evaluated to detect the protective effect of POC against IR injury in rats. Results: Induction of IR resulted in significant reduction in renal function, demonstrated by increase in plasma $\mathrm{Cr}$ and $\mathrm{BUN}$, histological changes and oxidative stress in both genders. Application of POC afforded significant protection against these injuries in male rats, namely decreased levels of BUN and $\mathrm{Cr}$, histological improvements and less oxidative damages. However, there were no significant differences in the above-mentioned parameters in female rats. Conclusion: While POC is shown to be beneficial against renal IR injury in male rats, it did not show any protective effect in female rats.
\end{abstract}

Keywords: sex difference, kidney, ischemia-reperfusion, postconditioning, AKI

Significant research and clinical progress have resulted from recognition of gender differences in cerebrovascular and cardiac diseases. There is also growing evidence that males and females have different abilities to tolerate the renal injury (15). Sexual dimorphism in renal injury has been a recognized clinical entity for at least 65 years, and sex steroid effects on renal tissue have been investigated for at least 30 years $(5,11)$. However, there is no information concerning sex differences about the protective effect of new methods of conditionings in the kidney. It is likely that the clinical benefit from this kind of knowledge can be expected in the relatively near future.

Renal ischemia as a consequence of arterial occlusion, shock and organ transplantation is a common cause of renal cell death, renal failure, delayed graft function and graft rejection (14). Although the return of blood flow to ischemic tissue may result in the recovery of

Corresponding author: Mehri Kadkhodaee

Department of Physiology, School of Medicine, Tehran University of Medical Sciences

Enghelab St. Poursina Ave., Tehran 14155-6447, Iran

Phone: 00982188259862; Fax: 00982166419484; E-mail: kadkhodm@tums.ac.ir 
normal function, paradoxically, the tissue may also be injured during the process of reperfusion (16). In accordance to reperfusion pathophysiology, several interventions have been proposed to reduce the extent of renal injuries. Studies have shown that ischemic preconditioning (PreC) reduces the renal IR injury. In this method, brief and frequent periods of ischemia are induced prior to a long-term ischemia in the kidney (27). However, for patients presenting unpredicted onset of ischemia, PreC strategy would be impossible to implement. Therefore, an interventional strategy that can be applied at the time of reperfusion offers greater potential. In this regard, ischemic POC, or injury-induced protection from a previous injury, is a recently described novel approach to attenuate renal IR injury that may have greater clinical potential (24).

Increasing evidence over the past decade has indicated that the production of reactive oxygen species (ROS), such as superoxide radical, hydrogen peroxide, and hydroxyl radicals contribute to the renal IR injury (23). The protection against ROS, provided by free radical scavengers produced during injury, further supports the hypothesis that these species are involved in the cellular pathogenesis of renal IR injury (25). Experimental data have demonstrated that renal POC can modulate oxidative stress and lipid peroxidation caused by IR injury in the male rats (23). However, there is no published study addressing that POC similarly confers reno-protection in females.

In our previous study, we analyzed and compared the effects of classical and remote ischemic postconditioning (POC) on the renal IR-induced acute kidney injury in male rats. The results confirmed the protective effects of both POC treatments comparing to IR group (9). In this study, we aimed to study the role of the gender on the beneficial effects of classical POC on IR-induced acute kidney injury. Therefore, we designed the present study in which the renal function and histology plus preservation of antioxidant levels in both female and male rats were evaluated.

\section{Materials and Methods}

Animals: Experiments were performed on sexually mature male and female Sprague-Dawley rats, weighing 250 to 300 grams. All procedures were approved by the Animal Ethics Committee of Tehran University of Medical Sciences (TUMS). The animals were bred and kept at the Animal House of TUMS in the condition of 12 hours lightness and 12 hours darkness with free access to standard rat chow and tap water.

\section{Experimental groups}

In this study, forty-eight uni-nephrectomized male and female rats were randomly divided into 6 groups of 8 rats as shown below (Fig. 1).

\section{General surgical preparation}

Rats were anesthetized with sodium pentobarbital $(60 \mathrm{mg} / \mathrm{kg})$. After the induction of anesthesia, the animals were placed under an overhead lamp in order to avoid anesthetic hypothermia. Their temperature was monitored by using a rectal thermometer.

During the surgery, systolic blood pressure was monitored by the tail-cuff method connected to a pneumatic transducer using a Power Lab/4sp Data Acquisition System (Software Chart, version 5, AD Instruments, Castle Hill, Australia). All animals underwent right nephrectomy after median laparotomy. In IR groups, using a non-traumatic bulldog clamp, 45 minutes of left renal pedicle occlusion was induced followed by 24 hours of 


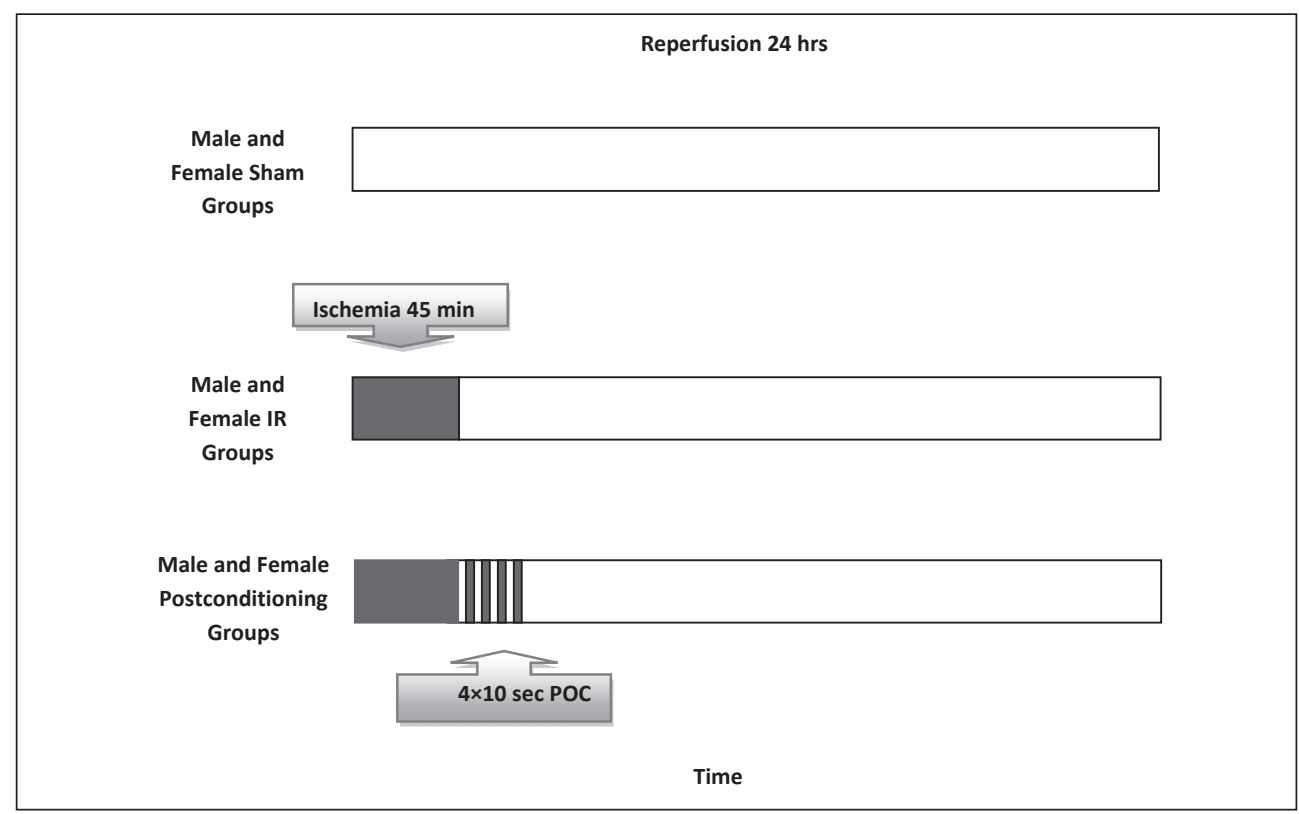

Fig. 1. Experimental protocols for animal groups

reperfusion (21). In sham groups, all of the above surgical procedures were applied except that IR was not induced. In POC groups, four episodes of 10-second ischemia and 10-second reperfusion of left renal artery (occlusion and release of renal blood flow) were applied immediately after 45 minutes of renal ischemia followed by 24 hours of reperfusion. Twentyfour hours later, left kidneys were harvested for histological and biochemical assessments and plasma samples were collected for renal functional monitoring by measuring blood concentrations of creatinine and blood urea nitrogen (BUN) levels.

\section{Functional assessments}

Blood samples were immediately centrifuged in $2000 \mathrm{rpm}$ for 15 minutes at $4{ }^{\circ} \mathrm{C}$, and the plasma aliquots were separated. Renal functional markers were measured with colorimetric methods using Hitachi 704 auto-analyzer, Japan, at $520 \mathrm{~nm}$ for BUN and $505 \mathrm{~nm}$ for creatinine.

\section{Histological examination}

The kidneys fixed in 10\% formalin, were paraffin-embedded and sectioned at $4-\mu \mathrm{m}$ thick. After deparaffinizing and gradual hydration, they were examined using hematoxylin-eosin staining. Histopathology for all kidneys was scored per section in at least 10 randomly selected non-overlapping fields at $\times 400$ magnifications of the sections. The following grading scale was used: $0=$ Minimal or no lesion; $1=$ Less than $25 \%$ of tubules were involved; $2=25-50 \%$ of tubules were involved; $3=$ More than $50 \%$ of tubules were involved. Grading of the renal tissue damages included presence of necrosis and other degenerative changes (vacuolization), tubular dilatation, luminal debris and cast formation and loss of brush borders from proximal tubules. 


\section{Measurement of kidney oxidative stress indices}

Renal superoxide dismutase (SOD) activity

Renal SOD activity was determined through the Paoletti and Mocali method (17). In this method, superoxide anions are generated from oxygen molecules in the presence of EDTA$\mathrm{MnCl}_{2}$ and mercapto-ethanol. NADPH oxidation is linked to the availability of superoxide anions in the medium. As soon as SOD is added to the assay mixture, it inhibits nucleotide oxidation. Therefore, at high concentration of the enzyme, the absorbance at $340 \mathrm{~nm}$ remains unchanged. For this purpose, $50 \mathrm{mg}$ kidney tissue samples were homogenized in $500 \mu \mathrm{l}$ phosphate buffer. After 20 minutes, the mixture was centrifuged in $4200 \mathrm{rpm}, 400 \mu \mathrm{l}$ supernatant was added to $1 \mathrm{ml}$ phosphate buffer and was then inserted in dialysis tubes inside the phosphate buffer for $15-18$ hours $\left(4{ }^{\circ} \mathrm{C}\right)$. The following solutions were subsequently added into the cuvette: $0.8 \mathrm{ml}$ triethanolamine-diethanolamine- $\mathrm{HCl}$ buffer, $40 \mu \mathrm{NADPH}$ solutions, $25 \mu \mathrm{l}$ EDTA- $\mathrm{MnCl}_{2}$ and $100 \mu \mathrm{l}$ from different samples. In the 5th minute, mercaptoethanol was also added. Absorbance changes were detected at $340 \mathrm{~nm}$. For the calculation, the following equation was used: Sample rate/control rate $\times 100=\%$ inhibition. Then the concentration of enzyme was obtained by the Paoletti's standard table.

\section{Renal MDA level}

Malondialdehyde was measured in the kidney tissue samples according to the Esterbauer and Cheeseman method (6). Briefly, $50 \mu \mathrm{L}$ supernatant was added to $50 \mu \mathrm{L}$ thiobarbituric acid which produced a pink pigment, having a maximum absorption at $532 \mathrm{~nm}$. The value of each sample was expressed as $\mu \mathrm{mol} / 100 \mathrm{mg}$ tissue.

\section{Statistical analysis}

All results were presented as mean \pm SEM. The data were analyzed using one-way ANOVA. To show the difference among the groups, Tukey's post hoc test was used. The differences between groups were considered significant at $p<0.05$.

\section{Results}

\section{Creatinine changes}

In male rats, plasma creatinine levels increased significantly in the IR group compared to sham-operated animals $(3.3 \pm 0.2 \mathrm{mg} / \mathrm{dl}$ vs $0.6 \pm 0.04 \mathrm{mg} / \mathrm{dl}, p<0.05)$. This value was significantly lower in the POC group compared to the IR group $(1.1 \pm 0.1 \mathrm{mg} / \mathrm{dl}$ vs $3.3 \pm 0.2$ $\mathrm{mg} / \mathrm{dl}, p<0.05)$. In female rats, plasma creatinine levels increased significantly in the IR group compared to sham-operated animals $(1.6 \pm 0.09 \mathrm{mg} / \mathrm{dl}$ vs $0.9 \pm 0.05 \mathrm{mg} / \mathrm{dl}, p<0.05)$ and no significant difference was seen in the POC group compared to the IR group $(1.9 \pm 0.1$ $\mathrm{mg} / \mathrm{dl}$ vs $1.6 \pm 0.09 \mathrm{mg} / \mathrm{dl}, p<0.05$, Fig. 2).

\section{Blood urea nitrogen changes}

In male rats, plasma BUN levels showed a significant increase in the IR group compared to sham-operated animals $(116.3 \pm 4.5 \mathrm{mg} / \mathrm{dl}$ vs $21.2 \pm 1.3 \mathrm{mg} / \mathrm{dl}, p<0.05)$. This value was significantly lower in the POC group compared to the IR group $(62.8 \pm 14.3 \mathrm{mg} / \mathrm{dl}$ vs 116.3 $\pm 4.5 \mathrm{mg} / \mathrm{dl}, p<0.05)$. In female rats, plasma BUN levels increased significantly in the IR group compared to sham-operated animals $(114.2 \pm 4.6 \mathrm{mg} / \mathrm{dl}$ vs $43.8 \pm 2.4 \mathrm{mg} / \mathrm{dl}, p<0.05)$ and no significant difference was seen in the POC group compared to the IR group (116.3 \pm $10.1 \mathrm{mg} / \mathrm{dl}$ vs $114.2 \pm 4.6 \mathrm{mg} / \mathrm{dl}, p<0.05$, Fig. 3 ). 


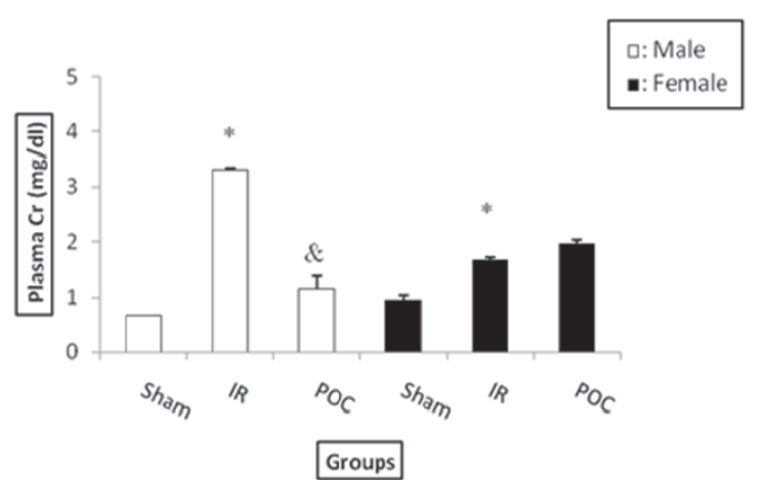

Fig. 2. Mean \pm SEM of creatinine levels in male and female Sham, Ischemia Reperfusion (IR), and Postconditioning (POC) groups. The values represent 8 rats per group. ${ }^{*}$ Significantly different from the same

- gender Sham group $(p<0.05) .{ }^{\&}$ Significantly different from the same - gender IR group $(p<0.05)$

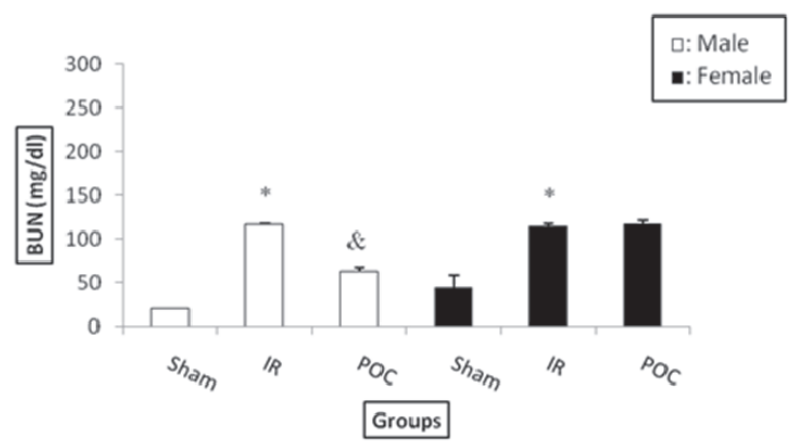

Fig. 3. Mean \pm SEM of BUN levels in male and female Sham, Ischemia Reperfusion (IR), and Postconditioning (POC) groups. The values represent 8 rats per group. ${ }^{*}$ Significantly different from the same - gender Sham group $(p<0.05) .{ }^{\&}$ Significantly different from the same - gender IR group $(p<0.05)$

\section{Renal oxidative stress parameters}

\section{Renal SOD activity}

In male rats, kidney SOD activity showed a significant decrease in the IR group compared to sham-operated animals $(5.9 \pm 0.4 \mathrm{U} / \mathrm{g}$ tissue vs $33.9 \pm 0.7 \mathrm{U} / \mathrm{g}$ tissue, $p<0.05)$. This value was significantly higher in the POC group compared to the IR group $(29.5 \pm 3.05 \mathrm{U} / \mathrm{g}$ tissue vs $5.9 \pm 0.4 \mathrm{U} / \mathrm{g}$ tissue, $p<0.05)$. In female rats, kidney SOD activity decreased significantly in the IR group compared to sham-operated animals $(13.1 \pm 1.7 \mathrm{U} / \mathrm{g}$ tissue vs $20.3 \pm 1.2 \mathrm{U} / \mathrm{g}$ tissue, $p<0.05$ ) and no significant difference was seen in the POC group compared to the IR group (17.7 $\pm 2.6 \mathrm{U} / \mathrm{g}$ tissue vs $13.1 \pm 1.7 \mathrm{U} / \mathrm{g}$ tissue, $p<0.05$, Fig. 4).

\section{Renal MDA levels}

In male rats, kidney MDA levels showed a significant increase in the IR group compared to sham-operated animals $(3.3 \pm 0.4 \mu \mathrm{mol} / 100 \mathrm{mg}$ tissue vs $2.06 \pm 0.1 \mu \mathrm{mol} / 100 \mathrm{mg}$ tissue, $p<$ 0.05 ) and decreased in the POC group compared to the IR group in the way that there was no significant difference from sham-operated animals $(2.4 \pm 0.3 \mu \mathrm{mol} / 100 \mathrm{mg}$ tissue vs $3.3 \pm 0.4$ 
$\mu \mathrm{mol} / 100 \mathrm{mg}$ tissue vs $2.06 \pm 0.1 \mu \mathrm{mol} / 100 \mathrm{mg}$ tissue, $p<0.05)$. In female rats, kidney MDA levels increased significantly in the IR group compared to sham-operated animals $(3.01 \pm 0.2$ $\mu \mathrm{mol} / 100 \mathrm{mg}$ tissue vs $2.5 \pm 0.2 \mu \mathrm{mol} / 100 \mathrm{mg}$ tissue, $p<0.05)$ and no significant difference was seen in the POC group compared to the IR group $(2.6 \pm 0.1 \mu \mathrm{mol} / 100 \mathrm{mg}$ tissue vs $3.01 \pm$ $0.2 \mu \mathrm{mol} / 100 \mathrm{mg}$ tissue, $p<0.05$, Fig. 5).

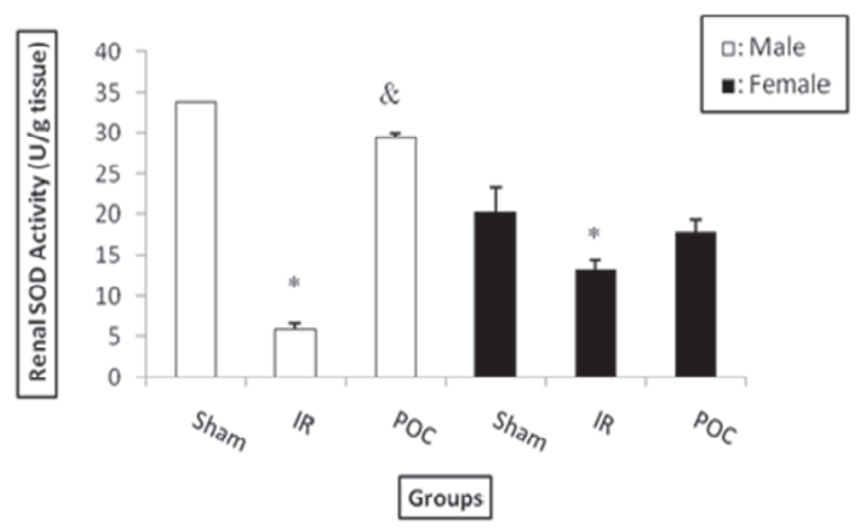

Fig. 4. Mean \pm SEM of Renal SOD activity in male and female Sham, Ischemia Reperfusion (IR), and Postconditioning (POC) groups. The values represent 8 rats per group. ${ }^{*}$ Significantly different from the same - gender Sham group $(p<0.05) .{ }^{\&}$ Significantly different from the same - gender IR group $(p<0.05)$

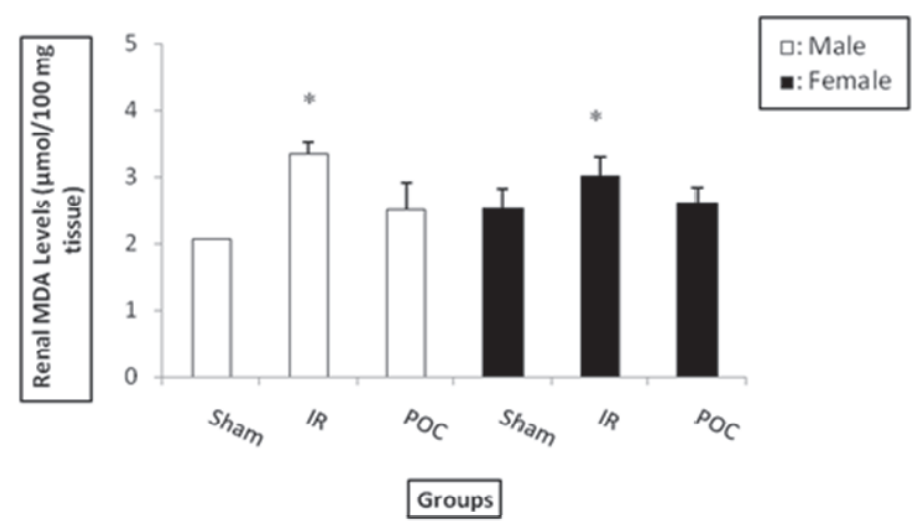

Fig. 5. Mean \pm SEM of Renal MDA levels in male and female Sham, Ischemia Reperfusion (IR), and Postconditioning (POC) groups. The values represent 8 rats per group. ${ }^{*}$ Significantly different from the same - gender Sham group $(p<0.05)$

\section{Histological findings}

In the kidneys of sham-operated animals of both male and female rats, despite the unilateral nephrectomy, the changes were minimal by light microscopy possibly due to physiological adaptations to nephron loss (Fig. 6A, Fig. 7). In the female IR group, there were no destructive and severe changes in renal tissues comparing to the sham-operated one (Fig. 6/B/Female). The most noticeable changes were tubular flattening, attenuation of the tubular patency's and 
increase in tubular lumen diameter. Unlike the male IR group, there was no detectable sign of necrosis in female kidneys. Less tubular debris was seen. So the majority of the nephrons were open. However, there were frequent cellular vacuolation. Opposite to male rats, induction of post-conditioning (POC) in females had no significant effect on renal histological changes comparing to the IR group (Fig. 6C/Female).

Female

A
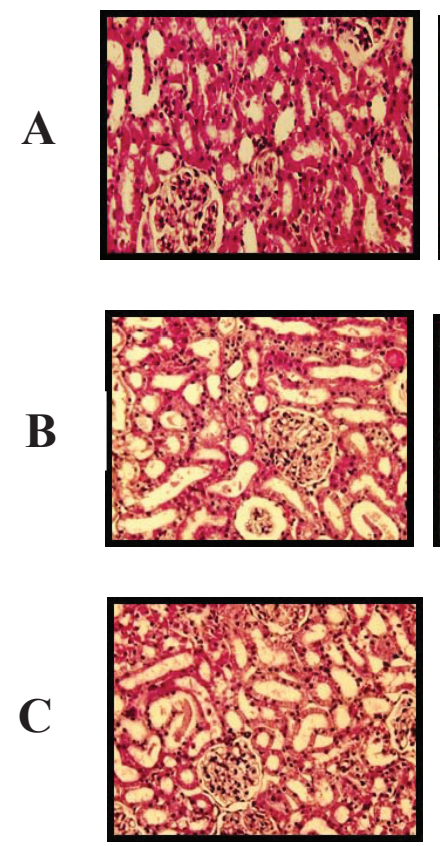

Male
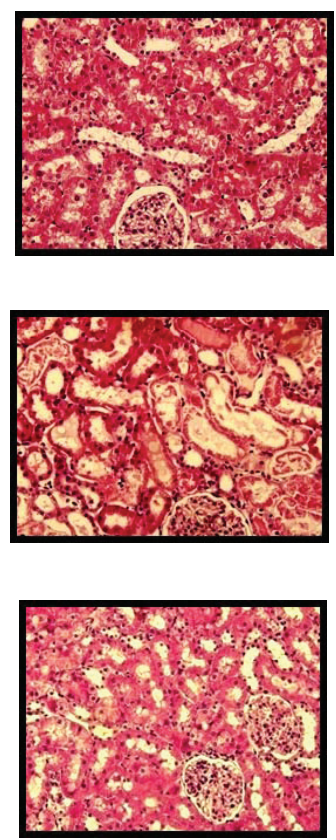

Fig. 6. Histological changes in the kidney in different groups. Magnification $\times 400$.

A: Sham Group, B: IR Group, C: POC Group

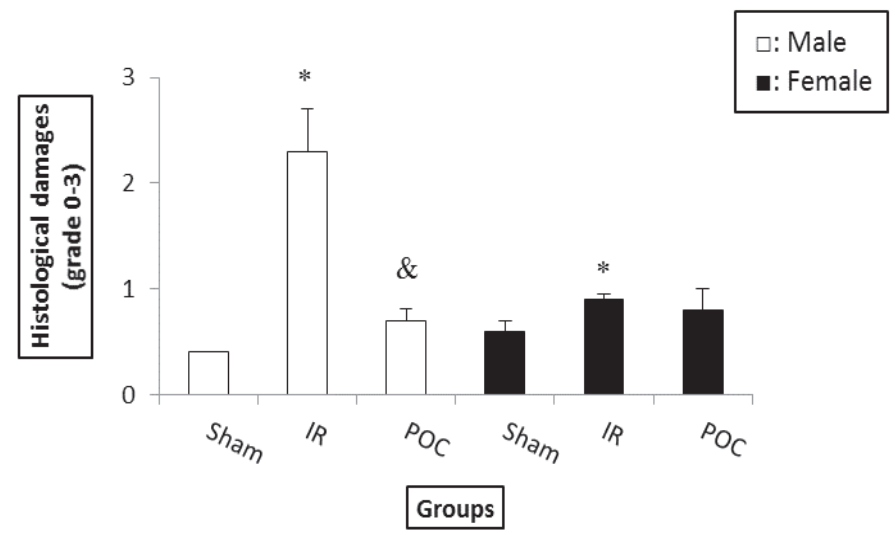

Fig. 7. Mean \pm SEM of Renal histological changes in male and female Sham, Ischemia Reperfusion (IR), and Postconditioning (POC) groups. ${ }^{*}$ Significantly different from the same - gender Sham group $(p<0.05)$.

${ }^{\&}$ Significantly different from the same - gender IR group $(p<0.05)$ 


\section{Discussion}

In this study we investigated the impact of gender on the beneficial effects of POC to reduce renal IR injury. For this evaluation, BUN and creatinine levels were used as renal functional markers. MDA and SOD activities as the indices of oxidant-antioxidant status of kidney tissues were also determined. We found that POC induced no significant changes in functional, histological and oxidative markers compared to the IR group in female rats.

Studies in experimental animals and in humans have shown that the rate of progression of renal disease is influenced by gender. For instance, male gender is more prone to development of renal dysfunction and hypertension in a rat model of endotoxic shock induced by i.v. injection of LPS (13). A study by Park et al. showed that male mice displayed significant deterioration of kidney function after bilateral renal ischemia within 30 minutes, whereas females were relatively protected (18). In another study, Fekete et al. showed that female rats had a significantly milder renal failure after renal IR as manifested by lower blood urea nitrogen (BUN) and plasma creatinine and less tubular necrosis (8). Consistent with those findings, our data showed that female rats were more protected from IR injury.

POC is a simple and harmless method that provides a new tool to protect an organ, namely heart, brain and liver $(10,26)$. Results from several studies suggested that the early moments of reperfusion were important in the pathogenesis of post ischemic injury, and that manipulation of this early reperfusion phase reduced renal IR injury (22). Recently, Yun et al. and Chen et al. described POC as a good strategy to reduce renal injury resulting from IR (1, 29). In another study they showed that POC attenuated renal dysfunction, demonstrated by significantly increased activity of antioxidants, including superoxide dismutase (SOD), and catalase (CAT). In their study, the level of malondialdehyde (MDA) and the activity of myeloperoxidase (MPO) decreased significantly in POC male rats (28).

Divergent results regarding the effectiveness of POC in isolated hearts have been reported between male and female rats. Lee et al. found POC as an ineffective method to reduce cardiac damage from long-term ischemic injury in isolated male or female rat hearts (12). In contrast, Crisostomo et al. reported that POC was more protective in male than female rat hearts by analyzing post-ischemic function (2). While several experimental studies indicate that estrogens have a cardioprotective role, in other studies; however, estrogens either do not protect or may even worsen post-myocardial infarction size. Demerouti et al. reported that POC protection could be reinstated after ovarectomy in female rabbits by demonstrating the effectiveness of POC in limiting the infarct size (3). POC was shown to be ineffective in reducing cardiac infarct size in female rats induced by either 30 or 45 minutes of ischemia (4). Similarly, in a study by Penna et al. after 30 minutes of ischemia, POC was less effective in female compared to male rat hearts in reducing infarct size (19). In the present study, while POC was effective in male rats to reduce the extent of renal functional, histological and oxidative damage, no beneficial effects was seen from the induction of POC in female rats.

It is generally agreed that a threshold of injury needs to occur for the mechanism of conditioning to be invoked (20). In the current study, the observed inability of the female rats to postconditioning may be due to the inadequacy of the index ischemia to achieve the injury required to stimulate protective processes (2). This suggests that females may require different degrees of ischemia-reperfusion injury to initiate POC protecting mechanisms.

Another explanation for the absence of POC-induced protection in female rats is that these methods are not as potent in females as in males. Females may require different periods and cycles of POC to be effectively conditioned. 
Taken together, in this study, while POC is shown to be beneficial against renal IR injury in male rats, it did not show any protective effect in female rats.

\section{REFERENCES}

1. Chen H, Xing B, Liu X, Zhan B, Zhu H: Ischemic postconditioning inhibis apoptosis after renal ischemia/ reperfusion injury in rat. Transplant Int. 21, 364-371 (2008)

2. Crisostomo PR, Wang M, Wairiuko GM, Terrell AM, Meldrum DR: Postconditioning in females depends on injury severity. J. Surg. Res. 134, 342-347 (2006)

3. Demerouti E, Andreadou I, Aggeli IK, Farmakis D, Zoga A, Gaitanaki C, Beis I, Anastasiou-Nana M, Kremastinos DT, Iliodromitis EK: Ovariectomy reinstates the infarct size-limiting effect of postconditioning in female rabbits. Cell Biochem. Biophys. 65, 373-380 (2013)

4. Dow J, Kloner RA: Postconditioning does not reduce myocardial infarct size in an in vivo regional ischemia rodent model. J. Cardiovasc. Pharmacol. Ther. 12, 153-163 (2007)

5. Duff GL, More RH: Bilateral cortical necrosis of kidneys. Am. J. Med. Sci. 201, 429-450 (1941)

6. Esterbauer H, Cheeseman KH: Determination of aldehydic lipid peroxidation products: malonaldehyde and 4-hydroxynonenal. Methods Enzymol. 186, 407-421 (1990)

7. Fairbanks SL, Young JM, Nelson JW, Davis CM, Koerner IP, Alkayed J: Mechanism of the sex difference in neuronal ischemic cell death. Neuroscience 219, 183-191 (2012)

8. Fekete A, Vannay A, Ver A: Sex differences in the alterations of $\mathrm{Na}(+), \mathrm{K}(+)$ ATPase following ischemia reperfusion injury in the rat kidney. J. Physiol. 555, 471-480 (2004)

9. Kadkhodaee M, Najafi A, Seifi B: Classical and remote post-conditoning effects on ischemia/reperfusioninduced acute oxidant kidney injury. Int. J. Surg. 12, 1162-1166 (2011)

10. Lansky AJ, Ng VG, Maehara A, Weisz G, Lerman A, Mintz GS: Gender and the extent of coronary atherosclerosis, plaque composition, and clinical outcomes in acute coronary syndromes. JACC Cardiovasc. Imaging 5, 262272 (2012)

11. Laszlo FA, Monus Z: The effect of estrogen, ACTH and cortisone administration and hypophysectomy on histological changes induced by unilateral renal pedicle clamping. Br. J. Exp. Pathol. 54, 306-311 (1973)

12. Lee DS, Steinbaugh GE, Quarrie R, Yang F, Talukder MA, Zweier JL, Crestanello JA: Ischemic postconditioning does not provide cardioprotection from long-term ischemic injury in isolated male or female rat hearts. J. Surg. Res. 164, 175-181 (2010)

13. Losonczy G, Kriston T, Szabo A, Muller V, Harvey J, Hamar P, Heemann U, Baylis C: Male gender predisposes to development of endotoxic shock in the rat. Cardiovasc. Res. 47, 183-191 (2000)

14. Mehta RL, Pascual MT, Gruta CG, Zhuang S, Chertow GM: Refining predictive model in critically ill patients with acute renal failure. J. Am. Soc. Nephrol. 13, 1350-1357 (2002)

15. Metcalfe PD, Meldrum KK: Sex differences and the role of sex steroids in renal injury. J. Urol. 176, 15-21 (2006)

16. Munshi R, Hsu Ch, Himmelfarb J: Advances in understanding ischemic acute kidney injury. BMC Medicine 2, 9-11 (2011)

17. Paoletti F, Mocali A: Changes in CuZn-superoxide dismutase during induced differentiation of murine erythroleukemia cells. Cancer Res. 48, 6674-6677 (1988)

18. Park KM, Kim JI, Ahn Y, Bonventre AJ, Bonventre JV: Testosterone is responsible for enhanced susceptibility of males to ischemic renal injury. J. Biol. Chem. 279, 52282-52292 (2004)

19. Penna C, Tullio F, Merlino A, Moro F, Raimondo S, Rastaldo R, Perrelli MG, Mancardi D, Pagliaro P: Postconditioning cardioprotection againt infarct size and post - ischemic systolic dysfunction is influenced by gender. Basic Res. Cardiol. 104, 390-402 (2009)

20. Pitcher JM, Nagy RD, Tsai BM, Wang M, Kherand A, Meldrum DR: Is the preconditioning threshold different in females? J. Surg. Res. 125, 168-172 (2005)

21. Sedaghat Z, Kadkhodaee M, Seifi B, Salehi E, Najafi A, Dargahi L: Remote preconditioning reduces oxidative stress, downregulates cyclo-oxygenase-2 expression and attenuates ischaemia-reperfusion-induced acute kidney injury. Clin. Exp. Pharmacol. Physiol. 40, 97-103 (2013)

22. Sener G, Tugtepe H, Yuksel M, Centinel S, Gedik N, Yegen BC: Resveratrol improves ischemia/ reperfusion induced oxidative renal injury in rats. Arch. Med. Res. 37, 822-829 (2006) 
23. Serviddio G, Romano AD, Gesualdo L, Tamborra R, Di Palma AM, Rollo T, Altomare E, Vendemiale G: Postconditioning is an effective strategy to reduce renal ischemia/reperfusion injury. Nephrol. Dial. Transplant. 23, 1504-1512 (2008)

24. Serviddio G, Venosa N, Federici A, Agostino D, Rollo T, Prigigallo F, Altomare E, Fiore T, Vendemiale G: Brief hypoxia before normoxic reperfusion (postconditioning) protects the heart against ischemia-reperfusion injury by preventing mitochondria peroxide production and glutathione depletion. FASEB J. 19, 354-361 (2005)

25. Singh D, Kaur R, Chander V, Chopra K. Antioxidants in the prevention of renal disease. J. Med. Food. 9, 443-450 (2006)

26. Vries HA, Ponds FA, Nieuwenhuijs VB, Morphett A, Padbury RT, Barritt GJ: Evidence that estrogen receptors play a limited role in mediating enhanced recovery of bile flow in female rats in the acute phase of liver ischemia reperfusion injury. Ann. Hepatol. 12, 130-137 (2013)

27. Wever KE, Menting TP, Rovers M, Van der vliet JA, Rongen GA, Masereeuw S, Ritskes-Hoitinga M, Hooijmans $\mathrm{CR}$, Warle M: Ischemic preconditioning in the animal kidney, a systematic review and meta-analysis. Plos One 7, e32296 (2012)

28. Yun Y, Duan WG, Chen P, Wu HX, Shen ZQ, Qian ZY, Wang DH: Ischemic postconditioning modified renal oxidative stress and lipid peroxidation caused by ischemic reperfusion injury in rats. Transplant Proc. 41, $3597-$ 3602 (2009)

29. Yun Y, Duan WG, Chen P, Wu HX, Shen ZQ, Qian ZY, Wang DH: Down-regulation of cyclooxygenase-2 is involved in ischemic postconditioning protection against renal ischemia reperfusion injury in rats. Transplant Proc. 41, 3585-3589 (2009) 